\title{
What is the Key to a Successful Transition for Indigenous Girls Moving From Torres Strait Island Communities to Boarding Colleges in Regional Queensland, Australia?
}

\author{
Francis Bobongie \\ Griffith University, Australia
}

\begin{abstract}
Each year, although there is a local secondary college in the region, indigenous girls in Years 7 12 opt to leave their Torres Strait Island Communities and attend boarding schools across the state of Queensland in Australia. During this transition process, students are confronted with many academic, social and cultural challenges and need to adjust accordingly. This paper focuses primarily on the stories and first hand experiences of Lisi, who graduated from one particular boarding college in regional Queensland ten years ago; it further details the experiences of other Torres Strait Islands girls who are currently attending the same school. The information presented in this paper is contextualized to this college, and highlights

factors that accommodate a smooth academic, social and cultural transition process; at the same time, it identifies actions taken by the boarding college to support this process. The paper uses qualitative methodology in combination with ethnographic narrative inquiry, focusing on the importance of storytelling as a less intrusive and more organic way of gathering information than other research methods. The data collected highlights the importance of cultivating an inclusive learning environment, and identifies the gaps that need to be addressed in order to further improve the transition process and student success in an academic, social and cultural context. Strategies for creating a successful environment involve a combined effort from all stakeholders. These include the indigenous communities within the extended kinship system; the immediate school community, both staff and students; and the larger school community comprising parents and board members.
\end{abstract}

\section{Introduction}

My connection to this project is both personal and professional. Although I was born and raised in Australia, I am connected to the Torres Strait Island region through my paternal grandmother, who was born on Thursday Island. This personal connection has always given me a privileged access to the region's culture and traditions. From a professional standpoint, first as an educator and now as an academic, I have seen first-hand the challenges faced by students, particularly girls, who make their journey from community to boarding school. A majority of Indigenous students live remotely, at long distances from their nearest secondary school, which means that many of them leave their communities for Boarding Schools to complete their secondary education. [1]

The boarding college discussed throughout this paper is located in regional Queensland. It is an all girl's college affiliated with a specific religious denomination. For the most part, boarding school staff endeavor to make the transition from community to college as smooth as possible. The aim is to create an inclusive learning environment that extends from classroom to the boarding house in which both non-indigenous and indigenous students can co-exist while understanding and accepting each other's complexities; this includes being able to navigate the academic divide common amongst many indigenous students, and to overcome social awkwardness and insecurities and cultural differences. It is essential that the girls feel comfortable so that they are able to learn effectively.

It is ten years since "Lisi", on whose story this paper draws extensively, first made her way to the boarding college. In comparing Lisi's story with that of current staff and students, this paper will identify the challenges that still exist for Torres Strait Island girls, highlight the strategies that the school has in place for a smooth transition, and identify the gaps that need to be addressed in order to ensure that future students enjoy a smooth transition.

\section{Ethnography and Narrative Inquiry in an Indigenous Context}

An individual's story is powerful. Story telling...the perspectives of women have become an integral part of all indigenous research [1].

I had arrived at the school and was waiting in the Indigenous Liaison Officer's (ILO) office. It was quiet...for now. However, I knew that once the bell rang it would be flooded with indigenous girls and 
their friends who would congregate and simply just hang out, eat, talk and socialise in the room. Because the majority of the girls were boarding students, this was a place where they felt comfortable and at home...a home away from home...the ILO, a substitute mother figure. As I sat completing my paperwork, one of the Torres Strait Island girls from Year 9 walked in, obviously upset. I asked her what was wrong and she began to explain: My teacher just told me that the Torres Strait Islands was not a part of Australia. I looked at her with a puzzled look on my face, not sure that I had heard right. She continued on: She said, that the Torres Strait Islands was not a part of Australia so I should just find information for my project about where I live. We had an argument because I was trying to tell her that it [the Torres Strait Islands] was a part of Australia and she just got angry at me! I was frustrated. (Observation FB, 2015)

The ethnographic study utilized three different data gathering methods. These include observations through immersion, focus groups and individual interviews. The study involved the following participants:

Table 1. Participants of the focus group

\begin{tabular}{|l|l|l|l|l|}
\hline & $\begin{array}{l}\text { Non- } \\
\text { Teaching } \\
\text { Staff }\end{array}$ & $\begin{array}{l}\text { Teaching } \\
\text { Staff }\end{array}$ & $\begin{array}{l}\text { Exec' } \\
\text { Staff }\end{array}$ & Other* \\
\hline $\begin{array}{l}\text { Non- } \\
\text { Indigenous }\end{array}$ & 1 & $1 * *$ & 2 & 0 \\
\hline Indigenous & 1 & 1 & 0 & $\begin{array}{l}\text { X ex } \\
\text { student }\end{array}$ \\
\hline
\end{tabular}

* There were two focus groups of six girls (boarders) from the Torres Strait Islands with a mix of Years $7-12$ in each.

** One of the teaching staff pulled out of the research project after she had finished her interview. The staff member was not comfortable going on record with what they had said during the interview process.

Utilizing narrative inquiry, or storytelling, as a preferred method of research presents an ideal opportunity to hear firsthand accounts of the experiences and challenges as faced during the transition process, as with the observation noted above. Hughes, More, \& Williams [3], discuss learning strengths in indigenous students and describe such students as being more oriented to storytelling sessions than didactic sessions. These stories are told in two different ways: storytelling as told by the researcher through immersion, and observation and storytelling as told by the participants through focus groups and individual interviews. The stories present both student and staff perspectives.

Throughout the course of the data collection process, it became clear that most of the indigenous students from remote communities in the Torres Strait Islands had experienced a considerable number of challenges throughout the transition process.
These were grouped into three main areas: Academic, Social and Cultural.

\section{Academic Challenges}

Every year the Prime Minister's office publishes an annual report "The Closing the Gap" which is a report card on how the Australian government is meeting their responsibilities in improving outcomes for Indigenous Australians. The "targets address the areas of health, education and employment, and provide an important snapshot of where progress is being made and where further efforts are needed" [1].

In terms of education and based on current NAPLAN (National Assessment Program Numeracy and Literacy) results, these are key points presented in the recent Closing the Gap 2017 report:

- Indigenous students across eight areas (reading and numeracy for Years 3, 5, 7 and 9) are achieving national minimum standards in NAPLAN. With the target to halve the gap for indigenous students by the year 2018, only one area (Year 9 numeracy) is on track.

- Numeracy and Literacy results are worse for Indigenous students coming from remote areas.

- On average Indigenous 15 year-olds are about two-and-a-third years behind non-Indigenous 15 year-olds in reading literacy and mathematical literacy. Indigenous boys are trailing their female peers in performance at school [1].

Issues specific to the Torres Strait Islands surrounding academic challenges include limited attendance. Regular attendance is not encouraged, meaning that indigenous students fall behind in areas of numeracy and literacy. The struggle with low literacy levels in schools affects all facets of academic learning [4]. Negative social attitudes in mainstream Australia [5], also contribute to poor school attendance and limited educational achievement.

In many communities of the Torres Strait Islands, it is not uncommon for children to be fluent in more than one language with English not usually a primary language.

Lisi, Gert and Janie discuss one of their biggest academic challenges: speaking, listening to and understanding English.

Lisi: (Part 1): I don't think my parents knew how scary it was, leaving home for the first time by yourself, travelling four stops away [by plane]. Yeah, I'd never do that to my daughter or son. I didn't know who I was looking for or who would be there waiting for me [when I arrived]. One of the supervisors was standing there with my name on a board. I was very shy. Yeah, the first couple of weeks the teachers at school tried to [talk to me] - we did a lot of breaking the ice activities. My biggest challenge was speaking English because I didn't - I 've had a few sentences 
here and there in primary school but I've never actually spoken a whole paragraph of English ... I knew my native tongue and Creole, which is broken English. There are a little bit of English words in there but not enough for you to understand a teacher...

Gert: In primary school we don't get taught English. We get taught our culture, you know, and then it's like a big difference when we go away to school. Sometimes in class I can't explain in English....and then I don't bother talking.

Janie: English is my fourth language. [In class] I can't keep up I dropped down from OP (Tertiary Level); it was so hard. I failed the first time. All the other girls in my class they understand but I don't want to keep the class behind so I just dropped out.

Falling behind academically has been linked to social and emotional issues, affecting student learning and vice versa [3] as can be seen from other challenges the girls faced.

Staff 7: Academically, they do struggle in school if they're put in a classroom and they're the only Torres Strait student there. Some girls go okay but some do walk out of class...crying because they're struggling, they don't know what to do. My biggest problem is the girls have trouble understanding what the teachers are saying because of the English as second language, the students don't understand the big words that the teachers use and not understand what they're expected to do. Just because they speak English doesn't mean they understand English.

\section{Social Challenges}

"In the local Indigenous universe, everyone is classifiable as kin" [6].

The importance of belonging to or being part of an Indigenous community is an important aspect of Indigenous identity. Knowing who you are and what family you belong to is of significance. Within their respective communities each person has their own responsibility, commitments and obligations which reach even to their extended families. An individual is not alone within a Kinship system. Each person is placed securely within the group. Roles within the Kinship system are determined according to age and gender, with significant cultural characteristics such as reciprocity and sharing [7]. The responsibility of providing for food and other essential necessities for living are not exclusive to one specific Indigenous household but are often spread across more than one dwelling [6].

Leaving a secure environment where one knows their place, and having to relocate geographically is a huge ask emotionally for a twelve-year-old. As a school, understanding the complexities and the significance of the "Kinship system" within an Indigenous community is one way of assisting with a smooth transition from Community to School when addressing the challenge of students dealing with homesickness.

Lisi: (Part 2): I didn't make friends for the first couple of months. I was really homesick but I was excited to experience something different...At home we go fishing. I think that was the one thing that I missed the most is walking down to the beach and then going fishing.

Many students experience homesickness while they are away at school and find it difficult to fit in with their peers, particularly when issues such as language and cultural differences see them isolated and not included in class. Some students do not return to school after they have gone home for the holidays.

Joan: If you're in a class and you're the only indigenous one in there, everyone gets into groups and you're the only one left out. You want to be included in the group. You feel like you should have another black person in the class with you. I always feel that way.

Kay: If I'm the only one [Indigenous Person] I don't feel included. It's like they don't want you to be there, like I'm different. I'm not saying they're racist but I just don't feel like they want you there. They'll talk but they just leave you out from the talk when you're in a group with them. I just sit and listen to them, I don't want to look like an idiot or try to ruin their conversation.

The disadvantage the girls experience in the classroom is not new, considering what they face generationally. For many indigenous parents it is hard to imagine a life without disadvantage, particularly when the challenges that young girls face in the village can be generational. For example: high levels of family employment, domestic violence, bullying, racism, poor housing, low employment and teenage pregnancies [8]. This means that student support and inclusiveness must also be extended to the family if the student is to successfully stay at school.

\section{Cultural Challenges}

Staff 7: Cultural challenges are a big issue because they're coming from home, they're leaving their culture and coming straight into a white man's world where they struggle, they struggle with that...Not having enough cultural activities here that reminds them of home. What they do at home and down here...it's two different worlds. I'd like to try and bring in more cultural activities but we do need our Torres Strait elders to come into the school...to do things with them.

Cultural challenges can include but are not limited to: parental and extended family involvement and financial responsibilities, students having access to cultural activities, missing family, food and cultural traditions, e.g. dance, being encouraged to 
communicate through their native language and perhaps one of the more significant challenges "sorry business".

The importance of parental involvement throughout the transition process is noted by Benvienste et al. [6], and may extend to members of the "kinship system" or extended family who are viewed as equally important. Everyone gets together and shares resources to assist their communal "investment" get through school.

Lisi (Part 3): I don't really know ... [how my family could afford to send me to school] .... It's not a question that I asked. It was better for me to go away to boarding school. It helped. It made me want to learn English and speak English because I didn't have Islanders around. In a way it made me feel independent.

Along with family, food and traditions are missed the most when making the transition to what is primarily a white Caucasian environment. Adjusting to unfamiliar food is a difficult process. Preparing and eating traditional food is integral to the Torres Strait Island way of life. These foods are often different to those eaten on the mainland. Other people do not always understand the girls' food choices in a cultural context.

Janie: I miss eating island food: fish, crayfish and turtle and not being able to see my mum and dad every day.

Clara: We miss seafood...we carry it down [from home] but it's kind of hard for us. It's easy to carry it down but it's hard to cook it because they [the other borders] get put off [by the smell] and we've got nowhere to cook it.

Judy: We always get lectured about our food from our boarding house supervisor, you know. She says: 'I don't know how you people can do that [eat turtle and dugong]. That's disgusting. That's cruel', and I'm like, well that's our culture.

The way culture is shared and responded to is dependent on who drives the process within the school.

Clara: I don't feel like I belong here because it's just - it feels like - it just feels like that we can't display our culture in any way.

Janie: There was one time where another girl was island dancing and the boarding supervisor told us not to do it and we were like why? She's like, 'because you can't do that'. And we said: 'Everybody has a right to culture'. She said: 'But you can't do it here'...we were offended.

One cultural celebration set aside every year for Indigenous Australians is NAIDOC Week. Originally NAIDOC stood for "National Aborigines and Islanders Day Observance Committee", which was one responsible for organizing national activities during this week. Now the name is given to the week itself. Both Indigenous and Non Indigenous people across Australia take part in the week's festivities.
The aim of 2017 NAIDOC theme - Our Languages Matter -was to emphasize and "celebrate the unique and essential role that Indigenous languages play in cultural identity, linking people to their land and water and in the transmission of Aboriginal and Torres Strait Islander history, spirituality and rites, through story and song" [10].

"Aboriginal and Torres Strait languages are not just a means of communication, they express knowledge about everything: law, geography, history, family and human relationships, philosophy, religion, anatomy, childcare, health, caring for country, astronomy, biology and food" Anne Martin (National NAIDOC Committee Co-Chair) [10].

Staff 7: Yeah, they speak to themselves in language and I'll never stop them from doing that, even in the office when they come in, if they speak language. If I'm in a meeting with them and they speak language I'll say can you speak English so I can understand it. But, when they're not in the classroom or out and about I'd rather them speak their own language because they have to keep that going.

An encouraging comment from Janie about her teacher at the end of our focus group was: My English teacher, she respects our culture so much. She adores it. She asks me so much questions. Whatever I say in class about home or whatever I have to question her about my school work and she'll sit and she'll help me until I get it correct.

Not all staff members have been so accommodating, considering the importance of maintaining language as part of maintaining their culture.

Clara: When we're speaking our language (in the boarding house) we're not allowed to. We understand that others can't understand us...once we were out here we were studying together and we were speaking in our language and then...the boarding executive... she walked in and then she said something to 'my friend'. My friend said in Creole "I sabe" which means I understand and then the head of boarding told her - "speak English, don't speak in your language because I don't know what you're talking about." She (my friend) said "yeah I understand" and the boarding supervisor came up this close and said "speak English" in her face and then "my friend" got upset...

When the two girls were asked if they are now allowed to converse in their own language they gave the following response:

Gert: Not really. We have to do it quietly. If we talk, we talk like this, you know (in a whisper), I don't feel like I belong here because it's just - it feels like that we can't display our culture and our language in any way.

"Sorry Business", a distinct and significant cultural practice in which extended indigenous 
Kinship systems contribute to the importance assigned to all matters surrounding death seems to be one of the more complex cultural traditions for mainstream educators to understand.

These ceremonial practices are diverse across Australia with strict cultural protocols that vary from one community to another and involve ceremonies that can last from several days up to some weeks, and can have over a thousand people in attendance. [11]

The following story puts into context the practice of "Sorry Business" within the Torres Strait Island community of boarders at this boarding college. The challenges faced by both staff and students highlight the importance of being able to navigate this cultural practice effectively in order to produce the best outcomes for the students.

Staff 7: Sorry Business - what happens? The last experience we had - a grandmother rang me and said to prepare the girls because their Aunty might pass. A staff member called them in and told them that we're going to expect bad news. Then that was in an afternoon. Then quarter to seven that next morning another phone call came from the same grandmother and saying that her daughter had passed away. A staff member had to come in at 7 o'clock to tell the girls that that news did happen. So then in the ILO office we've got all these girls crying, not much room to move around to comfort everyone. Other staff come over to help. Then we ended up going up to the prayer room and that's a much bigger room, it's like a big classroom. But that's not in use anymore. So we don't have an actual prayer room to go to when we have sorry business...the Torres Strait elder was actually sick...she couldn't come down. So we called on the Aboriginal elder, she came down straightaway. She helped us get through that day with the students. Then the grandmother organized for them to go home a couple of days later.

Sorry business is a big problem here because when they do get sorry business...they go home for the funeral and they come back and nothing is followed through with them. We suggest that the girls to go to a counsellor if they want to. We just keep checking on them to see how they're going. Sometimes they (the teachers) don't understand why the students have to go home straightaway. They expect the students to stay here at school, wait for the funeral date, then fly them home where they just have to go. Down here they don't understand that. We need more educating on that.

Well for this funeral they were away for about a month. So we booked their travels to go home, then we wait for the families to give us a date for when they're going to return. Then we just book it. But, like the school does keep an eye on that, they'd rather the girls go a couple of days before the funeral and come straight back where it just doesn't work that way.
The girls just catch up when they get back, try and catch up as much as they can. That's why we do need a tutor, someone here, to work with the students that go home with sorry business and come back and they have to catch up on all the school work. That doesn't happen a lot because the girls are still grieving. If they've got a lot of work to do they'll just give up because they've got too much and they're just struggling, it's easier for them not to do anything.

\section{Cultivating an inclusive environment with the implementation of strategies to improve upon student success}

Contextually, the inclusive environment must extend from school to the boarding house. In order to do this successfully, factors that contribute to student success need to be identified, and this should not only be inclusive of indigenous students, but nonindigenous students as well.

Student success is not only defined by academic standards. It also involves being able to survive in the three areas already mentioned. Guenther et al. [12], argue as to whether the current education system can be deemed successful by focusing on what Indigenous stakeholders see as the main purpose of education.

This includes:

1. Helping young people maintain a connection to their language, land and culture

2. Building a strong identity in learners

3. Helping young people to become strong in two worlds: both local and western

4. Support young people engaged in employment

Similarly, Benveniste, Dawson \& Rainbird [13] identify two overarching goals to take into consideration, with additional learning outcomes under each:

Firstly, the ability for students to "walk in two worlds": i.e. mainstream Australian society and the remote Aboriginal community. Part of this goal involved having the skills necessary to operate in mainstream society. Secondly, self-determination i.e. "“knowing who they are,' development of 'critical thinking' ability; and the skills and knowledge to 'decide their own futures"” [13].

With this in mind, it is necessary to implement the strategies that can best impact upon the academic, social and cultural challenges faced by the Torres Strait Island boarders and put these strategies into context according to the data collected by staff and students. The idea that students are able to "walk in two worlds" is ideal. The following are strategies that could potentially contribute to that ideal and take into consideration the data gathered from both students and staff. 


\subsection{Addressing academic challenges and the impact this has on overall learning}

Griffiths [14] identifies five components of best practice in indigenous education at an International level in Australia, New Zealand, the USA and in Canada. Two of these components are of significant interest and are relevant to the Boarding school studied. These best practices include: High quality committed teaching staff with emphasis on education fundamentals including numeracy and literacy; and Partnerships between students, schools, families and communities. Staff Member 5, is a non-indigenous administrator who has a lot to do with settling the students into the first two weeks of school. She highlights the importance of having adequate literacy skills and how this impacts upon all facets of school.

Staff 5: It's the literacy skills of the girls coming in from the Torres Strait that put them on the back foot for academic success. Now that's not all the Torres Strait girls. Not all, but probably 90 per cent of the girls coming in have lower literacy skills. So if you can't read something and understand it as well, you can't succeed in a subject and that does affect every subject really.

Empathy and respect for cultural identities need to be priority values to ensure support for Indigenous students in the learning environment [3]. Saara [3] indicates that the classroom environment takes on a positive change when the students' Indigenous Knowledges are recognized and utilized by the teacher. Reciprocal respect and a willingness to accept ownership of learning results in positive selfidentity and produces better outcomes for Indigenous students.

Staff 3: In our classroom context, generally I find them (the girls) reluctant to ask questions if they don't understand, [they are] very reserved and would rather just not submit something as opposed to seek out extra assistance. So what I've had to do in the past is organize a special tutorial where we sit down and I give them further assistance and scaffolding to give them some guidance.

Strategies to improve upon academic success: Academic success is two-fold. Including both students and staff in the learning process is

1. One-on one tutoring: Because the students arrive with low literacy and numeracy levels, an intense tutoring schedule to begin with would allow the students to make ground in areas where they are struggling. As their results improve, these sessions can become less frequent.

2. When organising classes be mindful of having more than one indigenous student in each class, particularly for students who are new to school and have left their community for the first time, e.g. younger students (Year 7 and 8) and students who are new to the school.
3. Education of the staff through in-service programs covering all topics specific to teaching and the understanding of indigenous students that attend the boarding college. Topics discussed should include but not be limited to cultural tradition and protocol and how to work effectively with indigenous students. Understanding each other comes as a result of open communication and support.

\subsection{Addressing the students and their social needs}

Academic and social factors relating to a smooth transition from community to school include, in a recent study done by Mander [15], homesickness, friendships and peer support, numeracy and literacy, prejudice, stereotypes and racism or intolerance.

Staff 6: They (the Torres Strait Girls) do get along with some of the non-indigenous girls, but I think those girls are more - the non-indigenous girls that create those friendships with the indigenous girls they're relaxed and open-minded and really see the bright personalities that they do have and enjoy that company. Whereas a lot of people - a few of the girls really separate themselves I've noticed. But in that I think the indigenous girls really do stick together and I think that's just a comfort thing for them and something that they're comfortable with.

While "comfort" is important, social acceptance within the boarding context will allow for a smoother transition. The importance of fostering a cohesive school community is to have everyone involved in the social development of all boarders. Just as parental communication with indigenous parents is of importance; so is parental communication with non-indigenous parents. The following suggestions are ways in which this particular boarding college can assist with this.

Strategies to improve upon social success:

1. Education of the staff through in-service programs covering topics specifically to dealing with the complexities of adjustment and integration into boarding school for both indigenous and nonindigenous students.

2. Create more opportunities for indigenous and nonindigenous students to spend time together outside of school and on the weekends.

3. Allow indigenous students to share their culture more with non-indigenous students in both school and boarding house contexts, e.g. NAIDOCC Week [15], Eddie Mabo Day. [16]

\subsection{Addressing cultural challenges; crossing between communities}


How can staff assist the students from Indigenous communities and in this case the Torres Strait Islands, maintain a strong sense of identity and connect with their culture while meeting the demands of boarding school? The stakeholders are parents and communities. There is a "heavy, emotional toll" for parents who send their children away to boarding school and are worried about ensuring that "their children retain a strong sense of identity and connection with their culture." [17]

Parents: All boarding-school stakeholders must explore how relationships between parents and schools can be strengthened and how effective communication can be fostered by using a range of strategies [9].

The boarding college in this study currently has its own strategies in place. A transition house deals with issues such as homesickness and behavioral challenges, and having boarding staff to get them settled at the beginning of the year is a priority.

Staff 4: The Transition house works very well, and we have girls who are home sick or having difficulty settling in, or, just say, if they do breach some of our rules...behavior policies and they (the parents) come and that really does work...I've found the parents to be very very supportive, yeah, which is very good. I can ring them and they are very understanding. What I like too... with the parents is, I ask them if they could speak to their daughters. That really does help, yeah, if it comes from them.

Staff 5: At the beginning of the year when the Torres Strait girls come in, they're dealing with being a long way away from home, different food, all these white people around, all these different rules in boarding, because it is community living. When we're trying to tell them all the information about being organized at school, time management, the importance of having the right books in the right place and all the things that you're allowed to do and these are the opportunities... Staff 7: Having more indigenous staff here at school and in boarding so that they can see them makes them feel a bit more comfortable and...they also need to have a lot of the cultural foods that they have at home.

Communities: Language and culture need not be barriers to learning, and ideally should be used as an asset. Linking with different communities' increases "awareness and connection" between the students, teacher and community. Ways in which this can happen include:

1. Use of culturally diverse instructional material

2. Helping students' cross borders

3. Appointing cultural guides from the community

4. Scaffolding instructions

All of these can be used to more effectively engage students in learning [3]. In the context of this boarding college, there could be more done to connect the school community and the indigenous communities in order to foster understanding culturally.

Strategies to improve upon cultural success: 1. While this can sometime be hard to do, connecting with local indigenous elders in the school community and maintaining regular visitations from them is essential.

2. Regular staff visitations to communities: Putting a face to the voice on the other end of the phone will help improve the level of communication.

3. Encourage cultural participation in local indigenous school and community events.

\section{Conclusion: After school...then what?}

Being able to achieve Year 12 or its academic equivalent sets a good foundation for university entrance or the beginning of a career, however for many Indigenous students, particularly those from remote areas, this can be a challenge. The retention rates of indigenous students in Year $7 / 8$ who have stayed at school until Year 12 was at 60 per cent in 2015 almost 30 per cent more than what was recorded in the 1990's, a vast improvement. Also revealed is that the rates are 10 per cent higher for Indigenous females at 64.1 percent compared to their Indigenous male counterparts at 54.9 percent [1].

That being said, what does cultivating an inclusive environment within this context achieve? Once these strategies are in place, what happens next? For some students it means being able to finish school; while for others it means successfully transitioning to a career after school. However, Osbourne and Guenther [18] note that "Very few remote students "succeed" in metropolitan boarding school contexts....and very few students imagine themselves taking up jobs in regional opportunities such as mining or mainstream tourism." Mander [19] comments that boarding schools In Australia need to develop in terms of supporting transition out of school into the workforce; one way of achieving this is by making stronger connections with family and community.

In terms of the school focused on within the study:

Staff 1: Our aim is to make the world we touch a better place. I think some of our girls do go back to their communities with qualifications in health and do make a difference in their communities. That's the ideal. That's fantastic. The next step up would be to make a difference in Australia or the world... but any of our girls, if we can get any of our girls to make a difference in their community that's fantastic.

Gina: My mum always tells us never to give up because she failed...she didn't go to University and she has high expectations for us.

The ongoing debate about whether or not boarding school is a good option for students from remote communities is not up for discussion, 
however it is fair to say that Gina and Lisi are very aware of the potentially positive impact boarding schools can have.

Lisi (Part 4): I have finished Year 12. I went back home. I was supposed to only have a couple of months' break but then my parents got sick. So I've put my life on hold to look after them. [If I could do anything I would go to university] and study to become a social worker.

Staff 1: When they (the girls) leave our little supportive community and they're on their own that's tough. That's that missing link for the next step but the ILO is working in that area and connecting with our past students more and more in that first year out. It's no good if we do everything we can and then set them loose. It has to actually continue after they graduate until we can get them within another network to nurture them. If we can't get them within another network, then they tend to just drop out.

Staff 7: Before they leave I try and set them up with career pathways...talk to parents and talk to universities or TAFE centres, try and set them up somewhere and I try and set them in the direction that they feel comfortable with. When they walk out of here I do worry about them [laughs] wondering what they're doing, if they did this, if they have done that. But then at the end of the day it's up to them and their parents then. Like I said before I do worry about them because knowing they've been here since grade eight to 12 and they've tried so hard to get this education you just hope they fall into the right hands when they leave. They really need someone based up in the Torres Strait, all on individual islands, to follow that through with them. Some of them won't know what to do by themselves. They need someone to say okay, you applied for this university, let's get you out there, let's set you up. But if there's no one there to do it won't happen. That's where the girls get stuck and then later I'll hear that they're pregnant or they're living with someone that's mistreating them. It's just heartbreaking to know what happens after.

One of the girls who graduated at the end of 2015 had wonderful things to say about their ILO.

Lou: How can I put this? She helps us work towards our senior certificate and helps us get into uni. (University) Yeah and even when we finish school she still helps us you know?

Inclusivity involved all stakeholders, from community members to parents, students, staff and board members. The level of support that enables each participant to understand and embrace each other's uniqueness contributes to successful outcomes for the students. Cultivating an inclusive learning environment means that all students, both indigenous and non-indigenous, are better equipped to succeed.

While this study is contextualized to a specific boarding college, the suggested strategies could potentially enhance the practice of any boarding college whose students, specifically girls, come from Indigenous communities.

\section{References}

[1] Australian Government, "Closing the Gap: Prime Minister's Report", Department of the Prime Minister and Cabinet, Canberra, 2017.

[2] Smith, L., Decolonising Methodologies: Research and Indigenous Peoples, 2nd Ed, Zed Books Ltd, New York, 2012.

[3] Saara, C., Young and Black and Deadly: Strategies for improving outcomes for Indigenous students, Australia College of Education, Deakin, ACT, (2003).

[4] N. Purdie, and S. Buckley, "School attendance and retention of Indigenous Australian students, Issue Paper No. 1, September 2010, Closing the Gap, Clearinghouse, Australia, 2010.

[5] Skwirk, "Challenges Facing the Indigenous Community Today", http://www.skwirk.com/p-c_s-17_u455_t-1230_c-4707/sa/sose/aboriginal-people-and-torresstrait-islanders/Indigenous-people-today/challengesfacing-the-Indigenous-community-today (Access Date: 25 May, 2014).

[6] F. Morphy. "Lost in Translation?: Remote Indigenous Households and Definitions of the Family". Family Matters 73 (2006), pp. 23-31.

[7] Dudgeon, P. Wright, M., Paradies, Y., Garvey, D., and Walker, I, 1 "The social, cultural and historical context of Aboriginal and Torres Strait Islander Australians," in Working together: Aboriginal and Torres Strait islander mental health and wellbeing principles and practice, Australian Institute of Health and Welfare, 2010, pp.25-42.

[8] C. Driscoll, and T. Lea., 2011. "Girls at the Centre", The Smith Family,http://www.thesmithfamily.com.au/ what-we-do/our-work/supporting-aboriginal-and-torresstrait-islander-families/girls-at-the-centre, (Access Date: 27 May, 2014).

[9] Benveniste, T., Guenther, J., Dawson, D. \& Rainbird S. "Out of sight, out of mind? Bringing Indigenous parent boarding school communication to go light", Paper presented at the 42nd Annual conference, Australian Association for Research in Education and New Zealand Association for Research in Education, Queensland University of Technology (2014).

[10] Australian Government, "2017 National NAIDOC Theme: Our Languages Matter", http://www.naidoc.org.au /2017, (Access Date: May 8, 2017).

[11] Carlson, B. and Frazer, R. "'It's like Going to a Cemetery and Lighting a Candle': Aboriginal Australians, Sorry Business and social media". AlterNative: An International Journal of Indigenous Peoples 11(3), 2015, pp. 211-24, doi: 10.1177/117718011501100301 
[12] J. Gunther, S. Disbray, and S. Osborne, "Building on 'Red Dirt' Perspectives: What Counts as Important for Remote Education?"/ The Australian Journal of Indigenous Education, 44 (Special Issue 02), 2015, pp. 194 - 206. doi: $10.1017 /$ jie.2015.20

[13] T. Benveniste, D. Dawson, \& S. Rainbird, "The Role of Residence: Exploring the Goals of an Aboriginal Residential Program in Contributing to the Education and Development of Remote Students", The Australian Journal of Indigenous Education, 44 (Special Issue 02), 2015, pp.163-172. doi: 10.1017//jie.2015/19

[14] A. Griffiths, "The Components of Best-Practice Indigenous Education: A Comparative Review", The Australian Journal of Indigenous Education, 40, 2011, pp. 69-80, doi: 10.1375/ajie.40.69

[15] Australian Government, "About Naidoc Week"., The Official Naidoc Website, http://www.naidoc.org.au/about (Access Date: 16 July, 2017)

[16] Aboriginal Heritage Office, "Mabo Day", http://www.aboriginalheritage.org/news/2013/mabo-day/ (Access Date: 16 July, 2107)

[17] D.J. Mander, "Enabling Voice: Aboriginal Parents, Experiences and Perceptions of Sending a Child to Boarding School in Western Australia", The Australian Journal of Indigenous Education, 44 (Special Issue 02), 2015, pp. 173 - 183. doi: 10.1017/jie.2015.21

[18] S. Osburne and J. Guenther, "Red Dirt Thinking on Aspiration and Success", The Australian Journal of Indigenous Education, 42 (Special Issue 02), 2013, pp. 88 - 99. doi: 10.1017/jie.2013.17

[19] D.J. Mander, L. Cohen, and J.A. Pooley, "A critical exploration of staff perceptions of Aboriginal boarding students' experiences", Australian Journal of Education, 59(3), 2015b, pp. 312-328. doi: 10.1177/00049441560738 